\title{
Dominant communities and dominant designs: Community-based innovation in the context of the technology life cycle
}

\author{
Victor P. Seidel \\ F.W. Olin Graduate School of Business, Babson College, \\ Wellesley, Massachusetts 02457 USA, vseidel@babson.edu \\ Benedikt Langner \\ Bain \& Company \\ Karlsplatz 1, Munich 80335 Germany \\ benedikt.langner@bain.com \\ Jonathan Sims \\ Management Division, Babson College, \\ Wellesley, Massachusetts 02457 USA, jsims@babson.edu
}

\begin{abstract}
Online community-based innovation - whether through self-organized communities, firmcommunity collaborations, or innovation contests and crowdsourcing - is increasingly used as a source of technological advances, yet studies in this domain are often detached from considering the dynamics of technological evolution itself. Where technological advances reside (knowledge distribution), the degree to which innovation tasks can be specified (task decomposition), and the rate of technological progress (performance trajectory) all vary dramatically over the technology life cycle. These factors have implications for what forms of online crowds and communities are most likely to contribute technological advances. We provide a dynamic model of the expected "dominant communities" for technological advances at each phase of the life cycle, and we draw on examples from open source software and consumer 3D printing to illustrate the model. Our objectives are to determine how different forms of community-based innovation dominate at different times, to ground innovation models more firmly in material technological advances, and to provide focus for future research in this domain.

Acknowledgements: An earlier version of this manuscript was presented at the Academy of Management meetings and the meeting of the European Group for Organizational Studies (EGOS). We are thankful to Annabelle Gawer and special issue editors Karim Lakhani, Michael Tushman, and Teppo Felin, as well as three anonymous reviewers for comments on the manuscript. The second author acknowledges funding from the Green Templeton Doctoral Scholarship Fund and the Said Foundation of Said Business School, University of Oxford.
\end{abstract}


Firms have increasingly used online means to involve individuals as part of their innovation efforts and to tap into a broad market for ideas (Felin and Zenger, 2014; Lakhani et al., 2013b). What we will broadly term "community-based innovation" includes a spectrum of approaches, such as the use of self-organized online communities (O'Mahony and Ferraro, 2007), firm-community collaborations (Jeppesen and Frederiksen, 2006), and online innovation contests and crowdsourcing (Piller and Walcher, 2006; Jeppesen and Lakhani, 2010). This range of community-based approaches is increasingly used to advance new technological innovations. While software technologies related to open source initiatives are perhaps the best known examples of using online communities for innovation (Lee and Cole, 2003; Fosfuri et al., 2008), a range of technological advances are now commonly sourced this way, from vehicle innovations (Seidel and Langner, 2015; Murray et al., 2012) to computational biology methods (Lakhani et al., 2013a).

Recent research has worked to unpack how organizations choose among different approaches to community-based innovation as sources of insight (Lakhani et al., 2013b; Felin and Zenger, 2014). Different approaches to community-based innovation include self-governing communities featuring members who collaborate intensely and share goals and values; innovation contests with broad communities of relatively disconnected individuals, often labeled "crowdsourcing"; or intermediate approaches of firm-hosted communities that often combine interaction among community members and competitive dynamics. Various studies have examined why certain forms of community-based innovation are employed. For example, the presumed location of useful knowledge and the nature of the problems to be solved can both explain the approach chosen (Felin and 
Zenger, 2014; Afuah and Tucci, 2012), and a firm has options in how they assess the strategic landscape in differentiating their community-based approach from others (Lakhani et al., 2013b; Boudreau and Lakhani, 2009). While the location of knowledge and the task to be performed are both useful considerations in choosing which communities are most likely as sources of technological innovation, most current models do not account directly for the dynamics of the technology life cycle itself and how this might change the fit with different forms of community-based innovation over time.

An omission of technological evolution can impede the development of appropriate models of innovation, as a history of research on the technology life cycle has demonstrated the contingent nature of its phases on organizational design and action (Tushman and Anderson, 1990; Abernathy and Utterback, 1978; Tushman and Rosenkopf, 1992). Indeed, early work on the technology life cycle often looked at the influential role of offline communities in promoting certain technologies (Wade, 1995; Tushman and Rosenkopf, 1992); under current online community contexts, the scale and scope of community involvement would be further increased. Drawing on recent work that has highlighted the importance of understanding how firms may be guided to select different community-based approaches to innovation (Lakhani et al., 2013b; Felin and Zenger, 2014), we have the opportunity to directly link community-focused research to the technology life cycle, bringing a dynamic and process-focused approach to research in this area.

Our research objective is to understand when different forms of community-based innovation dominate as sources of technological advances during the technology life cycle. We develop a theoretical model of how the characteristics of each phase of the technology 
life cycle determine the fit with community forms, leading to a different "dominant community" form at each phase. We illustrate our model with examples from open source software development and consumer 3D printing technologies.

Researchers have suggested the relationship between communities and organizations along relevant life cycles needs further theory development (Fosfuri et al., 2011: , p. 234). Our goal is to explicitly address this need, and we make three main contributions. First, by theoretically grounding an analysis of community form in the context of the life cycle, we help explain past empirical findings that point to the rise and fall of different community forms over time. Second, by understanding expected shifts in the form of community-based innovation over time, we augment past models of technological and industry evolution with that of community evolution. Third, by charting how firms and communities together shift over time, we can establish implications for which organization design elements firms may need to attend to in their collaboration with communities.

Our approach is structured as follows. We first describe the main forms of community-based innovation, followed by a review of the technology life cycle. We then develop how the characteristics of each phase of the technology life cycle have implications for which community form will dominate as a source of innovation. In the final section, we discuss additional research that follows from our study and consider the organizational design implications for collaboration between firms and communities.

\section{Community-based innovation}


"Community-based innovation" is a term we use to describe innovation efforts among individuals connected online, encompassing a range of collaborative and competitive efforts. In this study we draw on a history of work that has explored the role of different forms of communities in innovation (Felin and Zenger, 2014; Lakhani et al., 2013b). The interest in online communities and innovation has been spurred by recognizing that the scale of innovation afforded by individuals connected online extends the scope of innovation provided by prior methods (Boudreau et al., 2011; Jeppesen and Lakhani, 2010). Online community-based innovation is powerful not only for the connections afforded but also by the ways in which it can extend community norms of interaction and governance, such as in mobilizing people to achieve a shared mission (von Krogh et al., 2012), establishing means of governance (O'Mahony and Ferraro, 2007), and creating the capacity for learning and building on the ideas of others (Langner and Seidel, 2015; O'Mahony and Lakhani, 2011).

In Table 1 we outline a typology of three forms of community-based innovation that are motivated across three dimensions: the locus of governance, the level of interaction between members, and the incentives to participate in the community. These dimensions are commonly used to delineate key elements of community forms of organizing (cf. O'Mahony, 2007; von Krogh et al., 2012). We describe each form briefly before motivating why the technology life cycle alters the context for which form is the most appropriate fit for innovation.

-- INSERT TABLE 1 HERE -- 
Self-organized communities (SOC) are those that typically emerge independently from firm activity. As outlined in Table 1, these communities typically govern themselves, setting up and elaborating upon their own rules and norms of participation (O'Mahony and Ferraro, 2007; O'Mahony, 2007). Members of these communities often have high levels of interaction, and they draw on intrinsic motivations to participate, such as a shared sense of purpose (Shah, 2006; Hertel et al., 2003). Prominent innovation examples include opensource software (OSS) platforms such as Linux (Torvalds, 1999) and the products and technologies from lead-user communities (Baldwin et al., 2006).

Firm-community collaborations (FCC) are forms under which communities and firms work together in complementary ways, often with shared governance and decisionmaking, as also outlined in Table 1 . Some communities may maintain their own identity and operate independently. Alternatively, the collaboration may be part of a firm-hosted community effort, where the firm establishes and actively maintains the community. In either case, individuals within the community often interact with each other but more likely at lower levels than within self-organized communities, and they also interact with members of the firm. Motivations for participation can be a mix of intrinsic and extrinsic rewards. Examples of firm-community collaborations include firm-hosted communities for musical software (Jeppesen and Frederiksen, 2006) or vehicle designs (Seidel and Langner, 2015), as well as efforts by firms to create products or services that complement the work of an external community, such as Red Hat software development for software distribution (Casadesus-Masanell and Llanes, 2011).

Innovation contests and crowdsourcing (ICC) provide a means for firms to source innovations from disparate individuals outside of the firm (Terwiesch and Xu, 2008; Afuah 
and Tucci, 2012). Of the three forms of community-based innovation, innovation contests are those most commonly associated with the term "crowdsourcing." Here, governance of individuals in the broader community is conducted almost entirely by the firm, and participants have little or no say. While the participants of innovation contests may form a community in the sense that they have a common purpose and abide by the same rules, often they are disconnected from each other with lower levels of interaction than in other forms. This minimizes their ability to influence the direction of the community. Participants in crowdsourcing are often less driven to participate by intrinsic motivations when compared with extrinsic motivation such as cash prizes. This form of communitybased innovation has been used both for solving specific technical challenges as well as to probe new opportunities with less direction. Examples of the former approach include technological challenges set on the InnoCentive platform (Jeppesen and Lakhani, 2010) and innovation on software algorithms as part of the Netflix challenge (Murray et al., 2012). Examples of the latter approach include contests to address carbon emissions solutions (NRG COSIA Carbon XPRIZE; Virgin Earth Challenge) and tidal energy production (Saltire Prize).

In whatever form, community-based innovation provides a means to access new knowledge, work on innovation tasks, and advance technological performance. We next consider the context of the technology life cycle and how the characteristics of knowledge, tasks, and technological performance change over time.

\section{The technology life cycle and innovation}


While recent innovation research has focused on new actors involved in innovation — namely those within communities and crowds - precedence has arguably been put on understanding these new actors in isolation from the context of technological evolution. Historically, communities have been understudied in the context of innovation (O'Mahony and Lakhani, 2011). It can also be argued that the recent increased research focus on communities has come at the expense of fully considering the dynamics of technological evolution. This relative omission is somewhat understandable, as foundational work on the technology life cycle was done primarily considering inter-firm competition. However, it is also surprising, as such work also attended to the critical role of offline communities in the development of technologies (Wade, 1995; Tushman and Rosenkopf, 1992; Rosenkopf and Tushman, 1998). A history of studies related to a "sociology of technological evolution" (Tushman and Rosenkopf, 1992) fundamentally intertwines organizations, communities, and technological artifacts. In this section we briefly outline the elements of the technology life cycle that are important in understanding how the life cycle affects the nature of community-based innovation.

While different researchers have described the technology life cycle in slightly different language and with different parsing between distinct phases (cf. Tushman and Rosenkopf, 1992; Utterback and Suarez, 1993), we will outline three primary life cycle phases in the following sections: I) a pre-dominant design phase that encompasses the "era of ferment" leading up to the establishment of a "dominant design" that settles a technological order; II) a post-dominant design phase of incremental technological advances under relatively constant progress; and, III) a phase of decreasing returns and an active sensing for a new technological discontinuity. These three phases are related to the 
long-standing model of the technology cycle, as outlined in Figure 1. Rather than consider just two eras (i.e. preceding and following a dominant design), the distinction of three phases (noting changes in relative performance returns) will be important to specify in relation to the S-curve of technology performance.

\section{-- INSERT FIGURE 1 HERE --}

The three main phases can be mapped in relation to the "S-curve" of technology performance (Foster, 1986; Christensen, 1992), as given in Figure 2. While by necessity the technology S-curve is a stylized approach to portraying reality, it has been seen in industries such as disk drives, automobiles, sailing ships, semiconductors, tires, and energy technologies (Schilling and Esmundo, 2009; Christensen, 1992; Foster, 1986). With each increment of effort (and if effort is constant, then this is the same as each increment of time), the performance of a technology is expected to follow an S-curve form, eventually reaching a physical limit within a given technological domain (Christensen, 1992; Fosfuri et al., 2008; Schilling and Esmundo, 2009). This limit may or may not be reached; while the technology life cycle and the technology S-curve are typically represented as completing a full cycle, a technological discontinuity can occur at any point in this process due to the discovery and implementation of a new technological order. In following sections, we will motivate how changes in knowledge distribution and task decomposition over the technology life cycle, combined with the changing nature of performance trajectory, will have implications for community-based innovation, but first we consider 
how the stylized model of a technology life cycle fits relates to broader technological systems and product life cycles.

-- INSERT FIGURE 2 HERE -

\section{Multilevel technology life cycles and relation to product life cycles}

It is tempting to oversimplify an analysis by basing it on a single life cycle or Scurve. However, any technology exists as part of a multilevel hierarchy of technological systems, subsystems and components (Murmann and Frenken, 2006; Baldwin and Clark, 2000). In the historical example of the automobile, major technology subsystems included the engine, the body architecture technology, and the brakes. Each level of subsystem and its individual components were under distinct technology life cycles, with increases in technological performance (e.g. speed, body stiffness, braking distance) at each level (Argyres et al., 2015; Utterback and Suarez, 1993), and associated dominant designs for subsystems or components.

A more contemporary example of the hierarchical levels of technology can be seen in consumer three-dimensional (3D) printing. Consumer 3D printing has evolved with the development of a set of technologies that enable the simple and rapid production of physical objects. Users design objects on a computer and send printing instructions to a

device that creates the final product by depositing material in successive layers (Bechthold, 2015). A consumer 3D printing system is made up of several technology subsystems including the physical printer platform, the plastic filament technology, and the data handling system, among others. Each subsystem draws on different components, such as 
the printer platform making use of precision z-axis ball screw components and a filament extruder. Just as in the historical automobile example, consumer 3D printing is not a single technological artifact. It encompasses hierarchical levels of technologies.

Multiple levels of technologies and their associated life cycles underpin a designed product (Baldwin and Clark, 2000). In the historical automobile example, the Ford "Model T" product drew upon technologies such as the internal combustion engine, steel body production, and braking technology (Abernathy and Utterback, 1978; Tushman and Rosenkopf, 1992). This product enjoyed over a decade of success until new products challenged its dominance (Argyres et al., 2015). In the contemporary consumer 3D printing example, a number of products on the market have been developed by taking advantage of the confluence of technological subsystem development across producers. For example, Makerbot is one of several companies whose specific product draws from the consumer 3D printing array of technologies (West and Kuk, 2016) and who have helped establish the current dominant design in this domain. As we explore how the technology life cycle affects the dominant form of community-based innovation, we will be aware that technological advances can happen at different levels of a technology hierarchy.

In the next sections we develop a model of which form of community-based innovation is expected to dominate in the provision of technological innovations at each phase of the technology life cycle. The characteristics of technological innovation change over the three phases of the life cycle, particularly with respect to knowledge distribution and task decomposition (Lakhani et al., 2013b), as well as technological performance (Christensen, 1992; Foster, 1986). These differences will have implications of how well different forms of community-based innovation provide a fit for generating new 
innovations at each phase of the life cycle. An illustration of the resulting "dominant communities" at each phase is provided in Figure 3, charting the relative rise and decline of the expected influence of each community form.

\section{-- INSERT FIGURE 3 HERE -}

Similar to the construct of dominant designs - where one design may dominate but not be used exclusively (Murmann and Frenken, 2006) — the label of "dominant community" signifies that although one form of community may dominate, others are also still expected to be active as sources of ideas at lower levels. We will motivate that the reason each community form is expected to play a larger or smaller role over time is due to its relative fit with the nature of knowledge distribution, task decomposition, and performance trajectory at each phase. We will also provide empirical illustrations of these dynamics from two technologies: open source software and consumer 3D printing.

\section{Community-based innovation in the pre-dominant design phase}

The pre-dominant design phase of the technology life cycle (Phase I) is marked by great experimentation across organizations and communities. In the first column of Table 2 we outline the characteristics of the technology life cycle at this phase in terms of knowledge distribution, task decomposition, and performance trajectory. First, technological knowledge is widely and unevenly distributed among individuals across organizations and communities (Anderson and Tushman, 1990; Tushman and Rosenkopf, 1992). For example, in the development of the technologies underlying digital 
photography, elements of expertise were distributed across individuals in the optical camera, electronics, and film industries (Benner and Tripsas, 2012). A second characteristic of this phase is that technologies themselves are more likely to be in prototype form, and so there is a relatively low level of task decomposition. With such integral technologies, it can be difficult to specify to others how a development task is divided into discrete units. A third characteristic in this phase is that overall technological advancement is relatively slow (Schilling and Esmundo, 2009; Foster, 1986). With so many technological concepts competing and knowledge distributed widely, there is relatively little advance over time until there is a coalescing around a dominant technological design (Rosenkopf and Tushman, 1998).

\section{-- INSERT TABLE 2 HERE -}

As we outline in the further columns of Table 2, each form of community-based innovation can be assessed for fit to the characteristics of innovation at this phase of the technology life cycle. In doing so, and referring back to the development of Table 1, we consider how each form of community-based innovation has a locus of governance, a level of interaction between community members, and incentives to participate that together either provide relatively higher or lower fit to the characteristics of technological innovation when compared with other community-based forms.

At the first phase of the life cycle, self-organized communities (SOC) provide the overall highest fit to the characteristics of innovation, as noted in the appropriate column of Table 2. Self-organized communities retain decision-rights that enable them to determine 
where to search for knowledge that is widely dispersed. For example, examining an offline community in the development of the sports technologies underlying the "rodeo kayak," Baldwin and colleagues (2006) demonstrated how self-organized communities could advance a relatively simple sports technology toward becoming a dominant design in the emergent industry. Different rodeo kayak users explored and developed rodeo kayaks, thereby jointly optimizing designs while building on inventions within the community. Once this was developed, it became the dominant design.

Self-organized communities will exhibit the highest fit to the characteristics of task decomposition as well. Since tasks are difficult to break down discretely, advances are likely from individuals that benefit from repeated communication and interaction. Selforganized communities will be able to define their tasks in an integral fashion and make collective assumptions on what shape the emerging technology will take (O'Mahony and Ferraro, 2007). In an era of slow progress, members of self-organized communities often exhibit high levels of intrinsic motivation, which may be expected to sustain their efforts even when performance advances are slow, leading to higher fit for such communities as well. In sum, self-organized communities would be expected to be the dominate community form during this phase, providing a large proportion of innovations.

In contrast to self-organized communities, other forms of community-based innovation would be expected to have lower overall fit. For example, both firmcommunity collaboration (FCC) and innovation contests and crowdsourcing (ICC) typically rely on higher levels of task decomposition to enable collaboration on technological challenges (Jeppesen and Frederiksen, 2006) and so may have lower fit for providing innovations at this stage. Such forms of community-based innovation may also 
exhibit lower fit due to a mismatch of incentives being keyed more highly to extrinsic rewards, at a phase when it can be difficult for firms to specify such rewards and where performance gains are limited.

While some innovations may emerge from these other two forms of communitybased innovation, overall they would be expected to be at a lower level than self-organized communities, as is diagrammed in Figure 3. We next illustrate self-organized communities as a dominant community form at this phase with examples of open source software and consumer 3D printing technologies.

\section{Examples from software development and consumer 3D printing}

Open source software provided a new technological approach for software development. Its pre-dominant design phase was marked by multiple self-organized communities competing both against each other as well as established firms to define the next generation of software development. Knowledge was widely distributed, divided between firms that built proprietary software and the communities experimenting with open models. The establishment of Linux as a viable operating system and the associated technology of open source operating systems provide an example of the dynamics in this realm.

Before the dominant design of such Internet-enabled software development emerged, firms and self-governed open source communities viewed each other as competitors or even existential threats. Vertically-integrated firms sold software, and should such firms dissolve, users were typically left without support (West and Dedrick, 2001). In 1991, Linus Torvalds centralized knowledge distribution when he invited other 
developers to contribute to his new Linux initiative to provide a free alternative to expensive proprietary software. Torvalds was able to rely on others to help him build Linux by harnessing a close-knit community that could work through initial challenges even if problems were not well-specified and tasks hard to decompose. According to Torvalds, Linux could not have grown as fast as it did without the community, writing at the time that, "The power of Linux is as much about the community of cooperation behind it as the code itself." (Torvalds, 1999). High interaction between members and intrinsic motivations to persevere were critical to the development of open source software (von Krogh et al., 2012).

We can also consider the first phase of the consumer 3D printing technology life cycle. While industrial high-performance 3D printing of physical objects had been established for a time, consumer-focused technologies were slow to develop, due both to high costs and limited knowledge of how the technology could be used in this domain. Similar to the loose communities of "hacker" hobbyists responsible for the early development of open source software, consumer 3D printing was initially embraced by "makers," individuals who had intrinsic motivations to create and share designs (Anderson, 2012). Initially, knowledge was widely distributed, being somewhat isolated and protected by patents held by firms pursuing non-consumer applications of the technology. By the early 2000 s, when patents from early $3 \mathrm{D}$ printing technologies were beginning to expire, makers formed self-organized communities that continued to develop these technologies (Bechthold, 2015). The work of one community in particular, RepRap, helped drive a dominant design for printing when they released their first "open source" 3D printer design in 2007 (Anderson, 2012; West and Kuk, 2016). RepRap's printers, made openly available, 
used fused-deposition modeling (FDM), a process in which plastic is melted and applied in layers to form a solid object, and this self-organized community helped spur developments in this area and the adoption of this primary technology, FDM (West and Kuk, 2016). In summary, and as outlined in Table 3, the first phase of the technology life cycle was marked in both examples by self-organized communities as highly active sources of innovation.

-- INSERT TABLE 3 HERE --

\section{Community-based innovation in the post-dominant design phase}

The post-dominant design phase of the technology life cycle (Phase II) is characterized by an era of incremental change facilitated by consensus on core elements (Anderson \& Tushman, 1990). A dominant design can be understood as an architecture that encompasses a recognized set of core components and features (Abernathy and Utterback, 1978; Tushman and Rosenkopf, 1992) versus those that are more peripheral. While dominant designs are often embodied in the first successful product that commercializes a technology, a broader view considers dominant designs not necessarily by a single product but by an acceptance of the categorization of a new technological approach (Suarez et al., 2015), at times defined by the "operational principle" of a set of products (Murmann and Frenken, 2006). For float glass technology for glass production for example, it was not just one product but a range of products employing this approach that established it as a new dominant design (Anderson \& Tushman, 1990).

In the first column of Table 4 we outline the characteristics of the technology life cycle at this phase in terms of knowledge distribution, task decomposition, and 
performance trajectory. First, knowledge consolidates across firms and communities, as firms and communities begin to share broad understandings of how to build incremental advances on the newly-settled dominant design. Second, tasks increasingly are able to be decomposed into constituent parts. And third, the performance trajectory is marked by steady advances (Schilling and Esmundo, 2009; Foster, 1986), drawing upon consolidated knowledge and cumulative innovation.

\section{-- INSERT TABLE 4 HERE -}

As we outline in the remaining columns of Table 4, each form of community-based innovation can be assessed for fit to the characteristics of innovation at this phase of the technology life cycle. Again, we consider how a form of community-based innovation has a locus of governance, a level of interaction between community members, and incentives to participate that together either provide relatively higher or lower fit to the characteristics of technological innovation.

At this second phase of the technology life cycle, firm-community collaboration (FCC) provides the overall highest fit to the characteristics of innovation, as noted in the appropriate column of Table 4. Firm-community collaborations work under shared decision-rights, where both firm and community can divide increasingly decomposable tasks and work on a consolidated knowledge base on how to make advances in their area of expertise. As an example in vehicle design, large firms have maintained control over large-scale manufacturing, but platforms either set-up by the firms themselves or by third 
parties in collaboration with firms have acted as sources of both styling and engineering innovations (Seidel \& Langner, 2015).

Since firm-community collaborations also feature a mix of interaction between members and also high interaction with firms, this form provides a good fit for mid-range task decomposition at this phase of the technology life cycle. With the ability to better specify tasks, firms may set up "toolkits" for innovation (von Hippel and Katz, 2002). The perceived support of the toolkit is a key factor determining an individuals' perceived empowerment to innovate (Füller et al., 2009). During this phase, making it easy for individuals to understand the task at hand enables them to contribute ideas, an important dimension for successful innovation (Füller et al., 2009; Piller and Walcher, 2006). Furthermore, an increasing use of extrinsic rewards provides a mostly positive fit for this community form, as the performance trajectory can help motivation based on some monetary or other extrinsic reward for new innovations. In sum, firm-community collaborations would be expected to be the dominate community form during this phase, providing a large proportion of innovations.

Self-organized communities (SOC) are not expected to provide as good a fit at this stage. As one example of lower fit, with higher decision-making rights the members of a community may neglect opportunities for collaborative innovation under a consolidated and shared knowledge base between firms and communities. Innovation contests and crowdsourcing (ICC) also provide lower fit at this stage. While tasks are more decomposable, there can still be challenges in specifying tasks at this phase for disconnected individuals competing in a contest. For example, it was found that the innovation contest broker InnoCentive had a large proportion of problems unsolved as they 
were ill-defined by the organizations initiating their competitions (Jeppesen and Lakhani, 2010).

While some innovations may emerge from these other two forms of communitybased innovation, overall they would be expected to be at a lower level than firmcommunity collaborations at this phase, as diagrammed in Figure 3. We next illustrate firm-community collaborations as a dominant community form at this phase with examples of open source software and consumer 3D printing technologies.

\section{Examples from software development and consumer $3 D$ printing}

A dominant design in software development emerged when proprietary and open source software not only co-existed but also increasingly complemented each other. Three patterns promoted the dominant design and fostered complementary firm-community collaboration. First, as knowledge about OSS consolidated across firms and communities, firms that once faithfully opposed OSS began to publicly endorse the communities responsible for its development, such as when Microsoft created the CodePlex Foundation. Second, communities themselves became more open to working with firms, sharing decision-rights between the two. Finally, this dominant design in software development allowed for the creation of new business models that depended upon firm-community interaction. Private companies such as Red Hat provided support services to companies using open source software, complementing the work of the community (CasadesusMasanell and Llanes, 2011). Firms that created complementary products would give away their internally-developed products using open source licenses (Fosfuri et al., 2008). In 
essence, the competition between firms and communities common in the pre-dominant design phase was replaced by collaboration in the post-dominant design phase.

In the example of consumer 3D printing, similar dynamics of moving from selforganized communities to firm-community collaboration were also apparent. At this phase, several community web sites promoted the dominant design of FDM by encouraging users to share designs and ideas, including Ponoko, MakeXYZ, Repables, and Yeggi (Moilanen et al., 2014), and importantly firms also began to host communities. For example, firmcommunity collaboration was essential to the growth of MakerBot, the largest consumer 3D printing firm. MakerBot created and sponsored the user community Thingiverse, where members were encouraged to both design and share their designs for 3D objects back to the community (Moilanen et al., 2014; West and Kuk, 2016). Through this community, MakerBot was able to simultaneously promote its own products and encourage the development of the consumer 3D printing market, and over 130,000 Thingiverse members contributed over 100,000 designs online (Bechthold et al, 2015). In both cases, and as summarized in Table 3, the changing dynamics of the technology life cycle laid the foundations for a shift from self-organized communities to firm-community collaboration as the dominant community form.

\section{Sensing the next technological discontinuity}

The final phase of the technology life cycle (Phase III) is marked by a period of diminishing returns within a given technological realm (Foster, 1986; Christensen, 1992), as was outlined in Figure 2. At any point in the life cycle a new technological discontinuity may emerge leading to a new pre-dominant design phase (Kaplan and 
Tripsas, 2008; Anderson and Tushman, 1990). Early sensing of the emergence of the discontinuity increases chances of success in the next cycle (O'Reilly and Tushman, 2008). In the first column of Table 5 we outline the characteristics of the technology life cycle at this phase in terms of knowledge distribution, task decomposition, and performance trajectory. First, knowledge distribution at this phase is likely to be defined by a redundancy of views within current organizational actors (Tushman and Rosenkopf, 1992), fostering incentives for searching new knowledge domains. For example, evidence from the typesetter industry suggested that users often recognized the opportunity of a new technology and innovated accordingly, creating the new dominant design based on a new technology (Tripsas, 2008). A second characteristic in this phase is that tasks are highly decomposed, reflecting the mature state of the technology. A third characteristic in this phase is that the performance trajectory is one of diminishing returns. While the postdominant design phase is characterized by steady incremental advances to technological performance (Foster, 1986; Schilling and Esmundo, 2009), at some point technological progress is expected to slow even with increased effort. This slowing of technological advance provides an acknowledgement that knowledge stocks between the firm and community have become redundant, spurring a dynamic of increased search for knowledge outside of existing firm-community collaborations.

\section{-- INSERT TABLE 5 HERE -}

Table 5 illustrates how each form of community-based innovation can be assessed for fit to the characteristics of innovation given the locus of governance, a level of 
interaction between community members, and incentives to participate that provide relatively higher or lower fit between community-based innovation and the characteristics of technological innovation.

At this third phase of the technology life cycle, innovation contests and crowdsourcing (ICC) provide the overall highest fit to the characteristics of innovation, as noted in the appropriate column of Table 5. Under innovation contests and crowdsourcing, decision-rights are retained at the firm level, enabling them to direct a broad search for new sources of knowledge. A central challenge in innovation is managing to break from the past and being able to sense the next opportunity (Soda and Bizzi, 2012). Exploration outside the current dominant design is the basis for sensing new technological discontinuities, such as engaging in innovation contests for new forms of technology (Di Gangi and Wasko, 2009).

The high level of task decomposition at this phase is such that specific calls for new techniques can be made with clarity to innovation contests or crowdsourcing platforms. Platforms like InnoCentive provide a means to encourage new solutions, and in fact many advances on this platform were solved by individuals from domains different to the one where most knowledge resided (Jeppesen and Lakhani, 2010). A knowledge broker like InnoCentive may be used across several firms, each specifying its own technological challenge (Verona et al., 2006) and benefiting from their ability to define a challenge in a way in which it is most likely to be solved. Instead of using virtual knowledge brokers, some firms may set up and host their own platforms for innovation contests and crowdsourcing. As opposed to innovation through firm-community collaboration, in phase 
three the lack of communication between individuals can help spur on exploration of new knowledge domains, avoiding "group think" that might occur due to collaboration.

The awareness of diminishing returns may spur firms to focus on setting extrinsic monetary rewards to foster new efforts. Even with relatively simple technologies, firms are likely to establish innovation contests to sense the next discontinuity, especially if they deal with relatively mature technologies. Procter \& Gamble $(\mathrm{P} \& \mathrm{G})$ is a firm that has indicated that it is open to accepting radical innovations in their underlying technologies and related product areas (Rohrbeck et al., 2010). This was depicted in a key slogan of their "Connect + Develop" platform: "Could your innovation be the next game-changing deal?" This program provided monetary incentives to individuals for advancing new technologies. By using such competitions for sensing technological discontinuities, firms hope to sense new opportunities not otherwise available to them. In sum, innovation contests and crowdsourcing would be expected to be the dominant community form during this phase, providing a large proportion of innovations.

Though innovation contests and crowdsourcing are expected to provide the highest fit, other forms may still provide innovations, as outlined in Table 5. For example, firmcommunity collaboration (FCC) can also play a role, though with possible challenges in its wide-scale implementation. Philips' "live simplicity" forum was an example of using an FCC approach focused on possible long-term developments (Rohrbeck et al., 2010). One of the key challenges to using an FCC approach to sense technological change is the organizational resource requirements that are needed. Organizations have to sustain a broad and ongoing interaction with the community, far above what would be required in a simple innovation contest (Füller et al., 2007). Research has shown that if the community 
only focuses on innovation activities or trends, that may not be enough to sustain a longterm interest in the community (Füller et al., 2008). Not only firms but also individuals within self-organized communities may recognize the opportunities for sensing a next technological discontinuity. In Figure 3 we indicate that not only is the dominant community active, but also other forms of community are active at lower levels. For example, self-organized communities contain many committed users of technology that have incentives to innovate (Füller et al., 2007), and these communities will be in a race against firms to define the next discontinuity.

\section{Examples from open source software and consumer 3D printing}

It is not clear yet whether the dominant design of software development is in the third phase of the life cycle. However, there are signs that both firms and communities may be more actively searching for the next discontinuity. For example, over two hundred different iterations (or "forks") of Linux have allowed the open source software to be used in a variety of devices, from Android-based cell phones to servers. While open source communities and firms can complement each other (West and Gallagher, 2006), the bonds within firm-community collaboration may be tested over time as community contributors see firms profiting from their work.

While consumer 3D printing is still in the post-dominant design stage of the technology life cycle, we can surmise how firms and communities may interact as they begin to search for the next discontinuity. Already, some of the collaboration between commercial 3D printing firms and communities is showing signs of strain. For example, Makerbot received criticism from community members for making several business 
decisions that conflicted with community priorities, including basing a proprietary 2012 printer design off a "fork" of the open RepRap project, changing the Thingiverse terms of use, applying for intellectual property protection for their own printer technologies, and selling to a large firm (Moilanen et al., 2014). Though the next chapter is yet to be written, changes in the nature of community-based innovation may result in a higher reliance on innovation contests and crowdsourcing of new technologies for consumer 3D printing over time.

\section{Discussion}

We have developed a model of innovation where different community forms serve as dominant sources of innovations during different phases of the technology life cycle. We provide three main areas of contribution. First, we have provided a theoreticallygrounded derivation of what types of communities are most likely to contribute advances over time, and we have illustrated our model with examples from multiple industries.

Second, our model augments models of technological and industry evolution in providing a means to understand how dominant communities evolve over time. And third, our work contributes a basis for considering how firms may alter their organization design elements to attend to collaboration with communities.

Our study has implications for at least two main areas of continuing research in this domain. First, by offering a new way to understand how not only technologies but also communities evolve over time, we provide implications for future research at the intersection of platform innovation and dominant communities. Second, we provide implications for how firms may need to alter their organizational design decisions when 
working with communities across the technology life cycle. We discuss both of these implications in turn in the next sections.

\section{Dominant communities, lock-in, and technological platforms}

Models of technological evolution and dominant designs have always understood the power of individual firms and offline communities in promoting one form of design over another. Cases recount how social forces work alongside technical dynamics to determine the settling of dominant designs. For example, how the QWERTY keyboard design beat other alternatives (David, 1985) and how microprocessor designs coalesced into common standards (Wade, 1995). In contrast to a model of a single design winner, the dominant communities model we present is one that shows a plurality of communities playing a role at each phase of the technology life cycle.

While a spectrum of approaches to sourcing community-based innovations remain, our model considers that there may be additional factors that support "lock-in" to a specific dominant community form. Similar to the lock-in effects common in standards-setting and platform architectures (e.g. Shapiro and Varian, 1999), the role of offline communities in establishing "bandwagon effects" has been seen in the evolution of technologies and markets, such as with microprocessors (Wade, 1995). Extended to the online world, a specific form of dominant community may continue over time due to network effects and the way in which both knowledge distribution and task decomposition support the status quo.

An example of dominant community lock-in is Wikipedia. Wikipedia (now part of the non-profit Wikimedia Foundation) was formed as one of several self-organized 
communities during the rise of Internet-enabled reference material. In the pre-dominant design phase, firms such as Microsoft (from the computing market) and Encyclopedia Britannica (from the reference material market) were all competing with self-organized communities to define how Internet-enabled reference material would be developed, edited, and distributed. The dynamics of knowledge distribution, abilities at managing task decomposition, and opportunities for performance improvements all combined with network effects to enable Wikipedia to lock-in and become the dominant general reference source. However, because firms (who retained deep knowledge in editorial control and publishing) and the Wikipedia community (which facilitated broad knowledge on subject matter) did not form a firm-community collaboration, the full capacity of Internet-enabled reference material may fail to be realized. Ten years after its founding, Wikipedia has struggled with bureaucracy and issues of editorial control (Halfaker et al., 2012). The case of Wikipedia combines a mix of technological and organizational issues and provides an example of how lock-in of dominant communities may lead to otherwise less than optimal outcomes for later stages of technology development. Additional research on the lock-in of dominant communities can explore the causes and consequences of lock-in across technological domains.

Further work can also extend the focus of technological innovation from specific core elements to how firms and communities together create technological platforms whose scope may be focused internally, across a supply-chain, or at the industry level (Gawer, 2014). In a platform-based perspective the impact of the effect of new innovations can be widespread, rather than focusing on the technological performance of a specific component or subsystem. This perspective can be seen with internal platforms at 
Black and Decker, supply-chain platforms at Boeing, or mobile applications at Apple (Gawer, 2014). The implication of our model is that firms may find different types of communities more likely to contribute innovations that may advance their development of not only component or subsystem technologies, but also new technological interfaces and modular architectures. Such new technological interfaces and modular architectures may help to define opportunities for platform-wide innovation and collaboration (Baldwin and Clark, 2000; Fjeldstad et al., 2012).

Our model of dominant communities has assumed a technological regime in which there is a degree of design complexity of the product, providing opportunities for external influence and contribution. Non-assembled or simple products—as well as process technologies - would be expected to have less opportunity for communities to develop innovations throughout the phases of the technology life cycle. Tushman and Rosenkopf (1992), proposed such diminishing influence of communities and organizations in shaping technological progress as complexity diminishes. We would expect our model would likewise have decreased amplitude for less complex technologies, as depicted in Figure 3. This could be the focus of future empirical examination.

\section{Implications for organization design}

Even though community-focused strategies are often desired by firms (Fosfuri et al., 2011), such "meta-organizations" (Gulati et al., 2012) that bridge firms and communities demand an organizational design that works outside the realm of formal authority. Indeed, it can be challenging for organizations to work productively in the context of communities, as typical organizational elements such as formal roles and legal 
mechanisms for organization may not always be appropriate for coordinating innovation work outside the walls of the firm. "These [existing] elements are inconspicuous, if not entirely absent, in clusters of firms and open communities that work effectively as a single organization.” (Gulati et al., 2012: , p. 572) If appropriate capabilities and organizational architectures are not in place, there is a risk that the organization will not successfully make use of any gathered insight or adapt to changing environments (Chesbrough and Crowther, 2006; Fjeldstad et al., 2012). To benefit from interaction with communities across all phases, organizations need to develop organizational design elements that effectively integrate community contributions into their own innovation processes (Fjeldstad et al., 2012). Furthermore, organizations need to use mechanisms to evaluate input, otherwise they risk information overload and potentially losing valuable contributions (Berg-Jensen et al., 2014; Di Gangi and Wasko, 2009). An organizational design that effectively integrates community knowledge can achieve outcomes that are "bigger than the sum of its parts" (Tzabbar et al., 2008).

Recent theoretical work on organization design in inter-firm alliance collaborations (Albers et al., 2016) also has implications for firm-community collaboration, by describing organization design parameters that play critical roles in coordinating collaborative efforts, specifically the design parameters of structural interface, specialization, and formalization. Structural interfaces describe the network of interpersonal ties among boundary spanners between the firm and community. Specialization refers to the degree firm members are dedicated to managing relations with a community. And formalization is the definition of specific procedures and processes for collaboration. These parameters may need to change as firms collaborate with different communities over time, as we discuss next. 
In the pre-dominant design phase, a challenge for firms is to understand and monitor the activities of a range of communities as potential collaboration partners in later phases. For example, during the pre-dominant design phase of tablet computing technologies, individuals from communities focused on related areas such as netbooks, laptops and smart phones could all be seen as relevant sources for innovation. At this stage, interfaces between firms and communities are more informal and come from unspecialized units in the firm, such as engineers or marketing managers scanning disparate communities. Levels of formalizing collaboration would be expected to be low, as the potential risk to organizations at this stage is that they may deploy valuable resources to both learn about and work with nascent communities whose future contribution remains uncertain.

The post-dominant design phase necessitates a shift in focus of firm capabilities and organizational design parameters across interface, specialization, and formalization. With the emergence of a dominant design, there is increased clarity as to which communities can be a source of partnership. Firm capabilities shift to establishing boundary-spanning interfaces between firms and community members, and these relationships are increasingly specialized and formalized. Firms need to effectively manage community relationships, including how to specify the tasks that can be completed in partnership with communities. Beyond task specification, research on long-standing firm-hosted communities has found active community management teams help to motivate and engage individuals in the community (Langner and Seidel, 2015). Risks of undervaluing community members' contributions may be reduced by creating specific roles within the organization to follow community developments, or relying on the input of 
those who have an understanding of community norms and governance, such as hiring from members of the community itself (Langner and Seidel, 2015).

During the third phase, the implication is that organizational capabilities may again focus on a broad search, as they reassess the value of their existing community relationships and focus more on innovation contests and crowdsourcing. The implication is that the interface between firms and communities may evolve to specialize and formalize around capabilities for contest design, as contests are more likely to be generative when the sponsoring firm develops expertise to articulate a clear technical or design challenge (Boudreau et al., 2011). In addition to considering issues related to task specificity, firms must also develop interfaces structures, specialized roles, and formalized procedures to consider participant eligibility, incentives, and the evaluation of contributions (Jeppesen and Lakhani, 2010).

\section{Conclusion}

We have worked to reintroduce a focus on the technology life cycle that in many ways has been neglected in recent scholarship on strategic organization, and we join calls for future empirical work that examines strategic models of innovation firmly within the context of life cycles (Fosfuri et al., 2011). On the one hand, recent research on community-based innovation has primarily and justifiably had to grapple with the emergence of this phenomenon broadly - from its early origins in lead-user research to the broader phenomenon of re-imagining entire industries through open source communities. Research has recently progressed to parsing out the contingencies of both how and when different forms of community-organization interaction are most productive (Lakhani et al., 
2013b; Felin and Zenger, 2014). While a technology life cycle lens was used in the past to understand phenomena at both industry and organizational levels (Anderson and Tushman, 1990), the time has arrived to bring this focus to the intersection of communities and organizations.

If new theories of innovation are divorced from an adequate appreciation for context, the failures of our models in both research and practical settings may lead to disillusionment and abandonment of all that was productive. Researchers in the domain of community-based innovation will likely be all too aware of how this burgeoning area in many ways mimics the interest in past management fashions for innovation or strategic renewal (e.g. Abrahamson, 1991). Therefore, an appreciation of how we need to introduce context and nuance into our research models is likely to be well acknowledged even if it is challenging to do.

The emergent work on interesting "market-hierarchy hybrids" (Felin and Zenger, 2011) such as crowdsourcing by organizations, and other forms of "meta-organizations" (Gulati et al., 2012) has pointed to the need to take into account organization design at the intersection of firms and communities. Our effort to think about organizations not only in the context of communities, but also in the context of continued technological evolution, points to the need for complex contingencies when considering organization design in more open settings - and in our discussion we have highlighted design parameters across structural interfaces, specialization, and formalization as elements that may have most relevance. While the nature of the task will predicate both the form of open and collaborative innovation that may be required and the implications for organization design (Tushman et al., 2012), the nature of the task itself takes place in the context of the state of 
the technology. The question is less "whether to be open?" and more "how and in what manner to be open?", as a stream of research looks at how different forms of openness are important for innovation (Cassiman and Valentini, 2009; Felin and Zenger, 2014; Lakhani et al., 2013b). Emerging models of organization design of these market-hierarchy hybrids will need to embrace the inherent tensions of this context, and our hope is that our model of dominant communities provides some guidance for the patterns by which such collaboration may play out.

Any model of innovation provides a window that not only sheds light, but also by necessity walls off other perspectives through its focus. By focusing on the neglected context of the technology life cycle, we risk taking for granted that the life cycle is something that is precisely knowable. As discussed, there is of course not one technology life cycle but a multilevel hierarchy of related life cycles at any one time (Murmann and Frenken, 2006). Together, these technologies make up the products we consume. Both for researchers and practitioners, the implication is not that we need to determine the technology life cycle of interest. Rather, we need to be attentive to an environment in which there are multiple technology life cycles underway within a given innovation domain. At multiple levels and different phases in time, there may be opportunities to engage with communities to explore advances across these ever-evolving contexts.

Through drawing upon prior research on community-based innovation within the context of technological evolution, we have motivated the contingent contributions of communities over time. We expect future studies that further probe the organization design parameters that play a role over the life cycle will be an important and necessary complement to the rich data now available on online communities themselves. We hope 
our study has provided a helpful framework for work in this area. In addition to providing multiple avenues for future study, our objective has been to determine why different forms of community-based innovation dominate over time. This has been achieved through grounding our innovation models more firmly in an elaborated sociology of technological evolution that works at the nexus of organizations, communities, and technologies. 


\section{References}

Abernathy WJ and Utterback JM. (1978) Patterns of Industrial Innovation. Technology Review, MIT 80(7): 40-47.

Abrahamson E. (1991) Managerial Fads and Fashions: The Diffusion and Rejection of Innovations. The Academy of Management Review 16(3): 586-612.

Afuah A and Tucci CL. (2012) Crowdsourcing as a solution to distant search. Academy of Management Review 37(3): 355-375.

Albers S, Wohlgezogen F and Zajac EJ. (2016) Strategic alliance structures: An organization design perspective. Journal of Management 47(3): 582-614.

Anderson C. (2012) Makers: The new industrial revolution, New York: Crown Business.

Anderson P and Tushman ML. (1990) Technological Discontinuities and Dominant Designs: A Cyclical Model of Technological Change. Administrative Science Quarterly 35(4): 604-633.

Argyres N, Bigelow L and Nickerson JA. (2015) Dominant designs, innovation shocks, and the follower's dilemma. Strategic Management Journal 36(2): 216-234.

Baldwin C, Hienerth C and von Hippel E. (2006) How user innovations become commercial products: A theoretical investigation and case study. Research Policy 35(9): 1291-1313.

Baldwin CY and Clark KB. (2000) Design rules: The power of modularity, Cambridge, Massachusetts: The MIT Press.

Bechthold L. (2015) 3D Printing: A qualitative assessment of applications, recent trends, and the technology's future potential. Munich: Technical Institute of Munich.

Benner MJ and Tripsas M. (2012) The influence of prior industry affiliation on framing in nascent industries: The evolution of digital cameras. Strategic Management Journal 33(3): 277-302.

Berg-Jensen M, Hienerth C and Lettl C. (2014) Forecasting the Attractiveness of Usergenerated Designs using Online Data: An Empirical Study within the LEGO User Community. Journal of Product Innovation Management 31: 75-93.

Boudreau KJ, Lacetera N and Lakhani KR. (2011) Incentives and problem uncertainty in innovation contests: An empirical analysis. Management Science 57(5): 843-863.

Boudreau KJ and Lakhani KR. (2009) How to manage outside innovation. MIT Sloan Management Review 50(4): 69-76. 
Casadesus-Masanell R and Llanes G. (2011) Mixed source. Management Science 57(7): 1212-1230.

Cassiman B and Valentini G. (2009) Strategic organization of R\&D: The choice of basicness and openness. Strategic Organization 7(1): 43-73.

Chesbrough H and Crowther AK. (2006) Beyond high tech: Early adopters of open innovation in other industries. $R \& D$ Management 36(3): 229-236.

Christensen CM. (1992) Exploring the limits of the technology S-curve. Part I: component technologies. Production and Operations Management 1(4): 334-357.

David PA. (1985) Clio and the Economics of QWERTY. American Economic Review: 332-337.

Di Gangi PM and Wasko M. (2009) Steal my idea! Organizational adoption of user innovations from a user innovation community: A case study of Dell IdeaStorm. Decision Support Systems 48(1): 303-312.

Felin T and Zenger TR. (2011) Information aggregation, matching and radical markethierarchy hybrids: Implications for the theory of the firm. Strategic Organization 9(2): 163-173.

Felin T and Zenger TR. (2014) Closed or open innovation? Problem solving and the governance choice. Research Policy 43: 914-925.

Fjeldstad ØD, Snow CC, Miles RE, et al. (2012) The architecture of collaboration. Strategic Management Journal 33(6): 734-750.

Fosfuri A, Giarratana MS and Luzzi A. (2008) The Penguin Has Entered the Building: The Commercialization of Open Source Software Products. Organization Science 19(2): 292-305.

Fosfuri A, Giarratana MS and Roca E. (2011) Community-focused strategies. Strategic Organization 9(3): 222-239.

Foster RN. (1986) Innovation: The attackers advantage, New York: Summit books.

Füller J, Jawecki G and Mühlbacher H. (2007) Innovation creation by online basketball communities. Journal of Business Research 60: 60-71.

Füller J, Matzler K and Hoppe M. (2008) Brand Community Members as a Source of Innovation. Journal of Product Innovation Management 25: 608-619.

Füller J, Mühlbacher H, Matzler K, et al. (2009) Consumer Empowerment Through Internet-Based Co-creation. Journal of Management Information Systems 26(3): $71-102$. 
Gawer A. (2014) Bridging differing perspectives on technological platforms: Toward an integrative framework. Research Policy 43(7): 1239-1249.

Gulati R, Puranam P and Tushman M. (2012) Meta-organization design: Rethinking design in interorganizational and community contexts. Strategic Management Journal 33(6): 571-586.

Halfaker A, Geiger RS, Morgan JT, et al. (2012) The rise and decline of an open collaboration system: How Wikipedia's reaction to popularity is causing its decline. American Behavioral Scientist: 0002764212469365.

Hertel G, Niedner S and Herrmann S. (2003) Motivation of software developers in Open Source projects: an Internet-based survey of contributors to the Linux kernel. Research Policy 32(7): 1159-1177.

Jeppesen LB and Frederiksen L. (2006) Why Do Users Contribute to Firm-Hosted User Communities? The Case of Computer-Controlled Music Instruments. Organization Science 17(1): 45-63.

Jeppesen LB and Lakhani KR. (2010) Marginality and problem-solving effectiveness in broadcast search. Organization Science 21(5): 1016-1033.

Kaplan S and Tripsas M. (2008) Thinking about technology: Applying a cognitive lens to technical change. Research Policy 37(5): 790-805.

Lakhani KR, Boudreau KJ, Loh P-R, et al. (2013a) Prize-based contests can provide solutions to computational biology problems. Nature biotechnology 31(2): 108111.

Lakhani KR, Lifshitz-Assaf H and Tushman ML. (2013b) Open innovation and organizational boundaries: Task decomposition, knowledge distribution and the locus of innovation. In: Grandori A (ed) Handbook of economic organization: Integrating economic and organizational theory. Northampton, MA: Edward Elgar Publishing.

Langner B and Seidel VP. (2015) Sustaining the flow of external ideas: The role of dual social identity across communities and organizations. Journal of Product Innovation Management 32(4): 522-538.

Lee GK and Cole RE. (2003) From a Firm-Based to a Community-Based Model of Knowledge Creation: The Case of the Linux Kernel Development. Organization Science 14(6): 633-649.

Moilanen J, Daly A, Lobato R, et al. (2014) Cultures of Sharing in 3d Printing: What Can We Learn from the Licence Choices of Thingiverse Users? Journal of Peer Production, Forthcoming. 
Murmann JP and Frenken K. (2006) Toward a systematic framework for research on dominant designs, technological innovations, and industrial change. Research Policy 35(7): 925-952.

Murray F, Stern S, Campbell G, et al. (2012) Grand Innovation Prizes: A theoretical, normative, and empirical evaluation. Research Policy 41(10): 1779-1792.

O'Mahony S and Ferraro F. (2007) The emergence of governance in an open source community. Academy of Management Journal 50(5): 1079-1106.

O'Mahony S and Lakhani K. (2011) Organizations in the shadow of communities. Research in the Sociology of Organizations 33: 3-35.

O'Reilly CA and Tushman ML. (2008) Ambidexterity as a dynamic capability: Resolving the innovator's dilemma. Research in Organizational Behavior 28: 185-206.

O'Mahony S. (2007) The governance of open source initiatives: What does it mean to be community managed? Journal of Management \& Governance 11(2): 139-150.

Piller FT and Walcher D. (2006) Toolkits for idea competitions: A novel method to integrate users in new product development. $R \& D$ Management 36(3): 307-318.

Rohrbeck R, Steinhoff F and Perder F. (2010) Sourcing innovation from your customer: how multinational enterprises use Web platforms for virtual customer integration. Technology Analysis \& Strategic Management 22(2): 117-131.

Rosenkopf L and Tushman ML. (1998) The coevolution of community networks and technology: Lessons from the flight simulation industry. Industrial and Corporate Change 7(2): 311-346.

Schilling MA and Esmundo M. (2009) Technology S-curves in renewable energy alternatives: Analysis and implications for industry and government. Energy Policy 37(5): 1767-1781.

Seidel VP and Langner B. (2015) Using an online community for vehicle design: Project variety and motivations to participate. Industrial and Corporate Change 24(3): 635-653.

Shah SK. (2006) Motivation, governance, and the viability of hybrid forms in open source software development. Management Science 52(7): 1000-1014.

Shapiro C and Varian HR. (1999) Information rules: A strategic guide to the network economy, Boston, Massachusetts: Harvard Business School Press.

Soda G and Bizzi L. (2012) Think different? An investigation of network antecedents and performance consequences of creativity as deviation. Strategic Organization 10(2): 99-127. 
Suarez FF, Grodal S and Gotsopoulos A. (2015) Perfect timing? Dominant category, dominant design, and the window of opportunity for firm entry. Strategic Management Journal 36(3): 437-448.

Terwiesch C and Xu Y. (2008) Innovation contests, open innovation, and multiagent problem solving. Management Science 54(9): 1529-1543.

Torvalds L. (1999) The Linux edge. Communications of the ACM 42(4): 38-39.

Tripsas M. (2008) Customer preference discontinuities: A trigger for radical technological change. Managerial \& Decision Economics 29(2/3): 79-97.

Tushman M and Anderson PC. (1990) Technological discontinuities and dominant designs: A cyclical model of technological change. Administrative Science Quarterly 35(4).

Tushman M, Lakhani K and Lifshitz-Assaf H. (2012) Open innovation and organization design. Journal of Organization Design 1(1): 24-27.

Tushman ML and Rosenkopf L. (1992) Organizational determinants of technological change: Toward a sociology of technological evolution. Research in Organizational Behavior 14: 311-347.

Tzabbar D, Aharonson BS, Amburgey TL, et al. (2008) When is the whole bigger than the sum of its parts? Bundling knowledge stocks for innovative success. Strategic Organization 6(4): 375-406.

Utterback JM and Suarez FF. (1993) Innovation, competition, and industry structure. Research Policy 22(1): 1-21.

Verona G, Prandelli E and Sawhney M. (2006) Innovation and virtual environments: Towards virtual knowledge brokers. Organization Studies 27: 765-788.

von Hippel E and Katz R. (2002) Shifting Innovation to Users via Toolkits. Management Science 48(7): 821-833.

von Krogh G, Haefliger S, Spaeth S, et al. (2012) Carrots and rainbows: Motivation and social practice in open source software development. MIS Quarterly 36(2): 649676.

Wade J. (1995) Dynamics of organizational communities and technological bandwagons: An empirical investigation of community evolution in the microprocessor market. Strategic Management Journal 16(S1): 111-133.

West J and Dedrick J. (2001) Open source standardization: the rise of Linux in the network era. Knowledge, Technology \& Policy 14(2): 88-112. 
West J and Gallagher S. (2006) Challenges of open innovation: The paradox of firm investment in open-source software. R\&D Management 36(3): 319-331.

West J and Kuk G. (2016) The complementarity of openness: How MakerBot Leveraged Thingiverse in 3D Printing. Technology Forecasting and Social Change 102: 169181. 


\section{Figures and Tables}

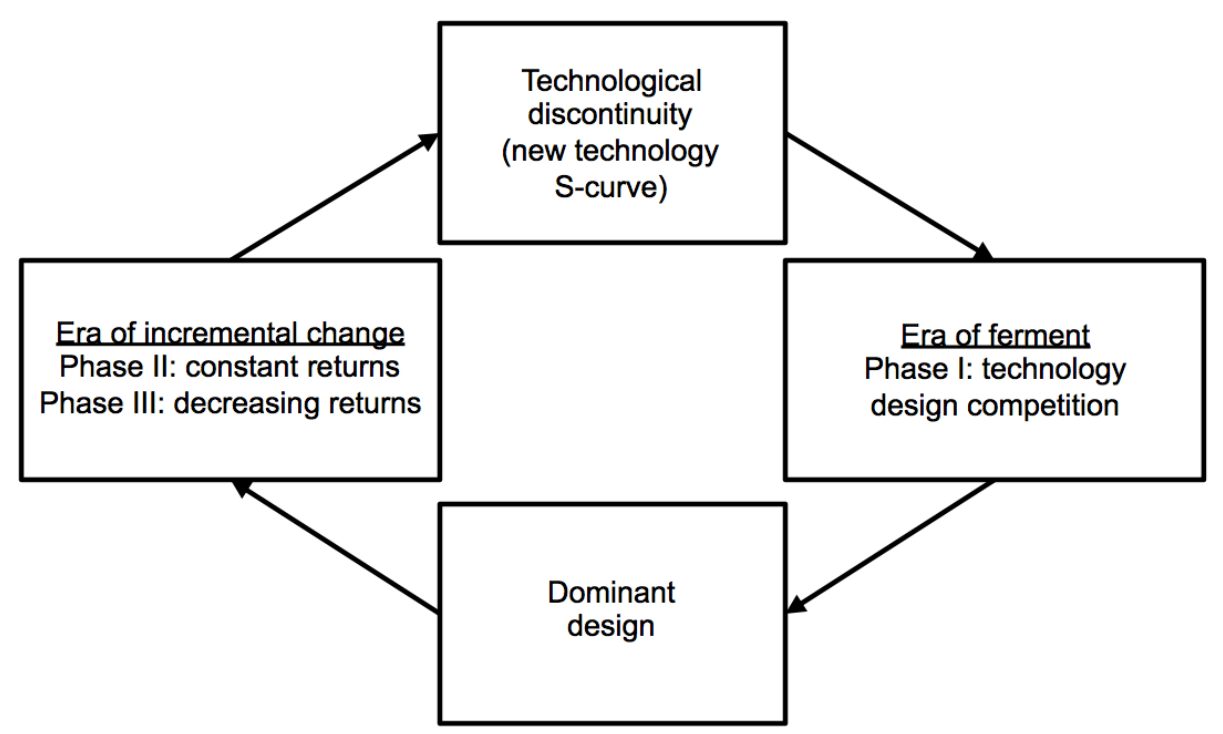

Figure 1: The technology life cycle with two eras and three distinct phases (Adapted from Tushman \& Rosenkopf 1992; Murmann \& Frenken 2006) 


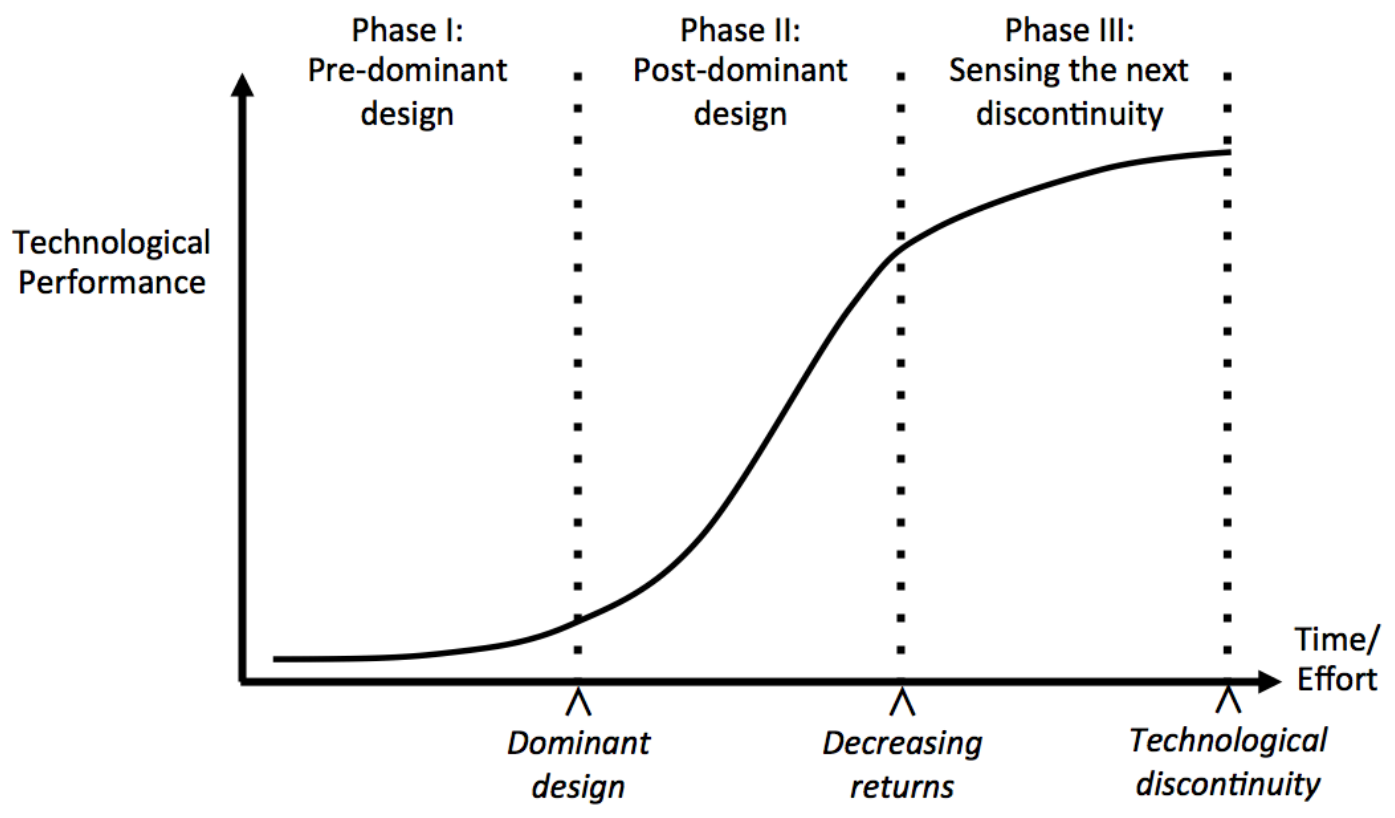

Figure 2: The technological performance S-curve through one technology cycle (Adapted from Foster, 1986) 


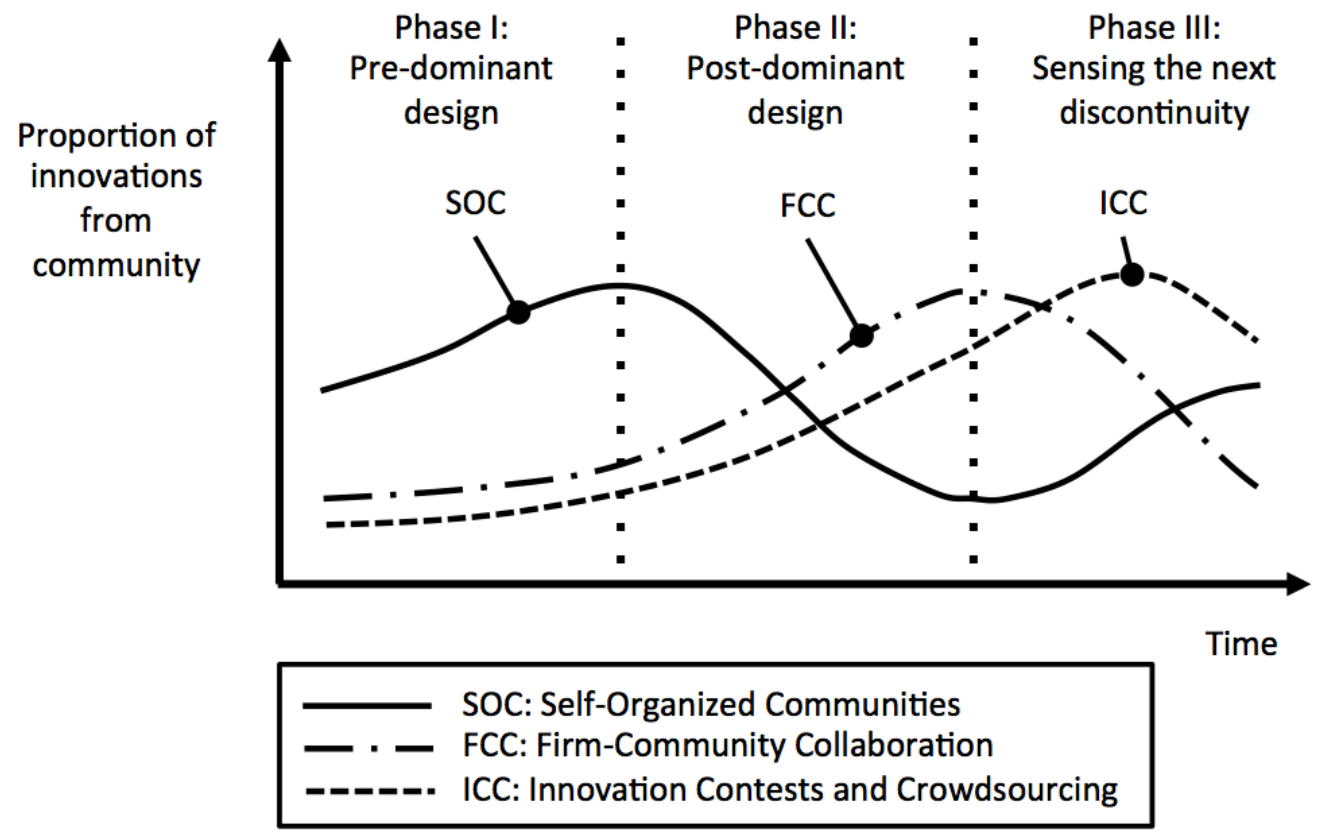

Figure 3: Relative proportions of innovations expected from different communities over the phases of the technology life cycle 
Table 1: Comparison of three main forms of community-based innovation

\begin{tabular}{lccc}
\hline & $\begin{array}{c}\text { Self-organized } \\
\text { community (SOC) }\end{array}$ & $\begin{array}{c}\text { Firm-community } \\
\text { collaboration (FCC) }\end{array}$ & $\begin{array}{c}\text { Innovation contests \& } \\
\text { crowdsourcing (ICC) }\end{array}$ \\
\hline Locus of governance & $\begin{array}{c}\text { Community members } \\
\text { hold key decision rights }\end{array}$ & $\begin{array}{c}\text { Shared decision-making } \\
\text { between firm and } \\
\text { community members }\end{array}$ & $\begin{array}{c}\text { Firms hold key decision } \\
\text { rights }\end{array}$ \\
$\begin{array}{l}\text { Level of interaction } \\
\text { between community } \\
\text { members }\end{array}$ & High levels of interaction & $\begin{array}{c}\text { Mixed depending on } \\
\text { community and } \\
\text { collaboration structure }\end{array}$ & $\begin{array}{c}\text { Typically lower levels of } \\
\text { interaction between } \\
\text { contest participants }\end{array}$ \\
$\begin{array}{l}\text { Incentives to } \\
\text { participate in } \\
\text { community }\end{array}$ & $\begin{array}{c}\text { Higher intrinsic and } \\
\text { lower extrinsic rewards } \\
\text { common }\end{array}$ & $\begin{array}{c}\text { Combination of intrinsic } \\
\text { and extrinsic rewards } \\
\text { common }\end{array}$ & $\begin{array}{c}\text { Higher extrinsic and } \\
\text { lower intrinsic rewards } \\
\text { common }\end{array}$ \\
$\begin{array}{l}\text { Empirical examples } \\
\text { and context) }\end{array}$ & $\begin{array}{l}\text { Drupal (web publishing) } \\
\text { RepRap.org (3D printing) }\end{array}$ & $\begin{array}{l}\text { Local Motors (vehicle } \\
\text { design) } \\
\text { Red Hat (software }\end{array}$ & $\begin{array}{l}\text { Innocentive (technology } \\
\text { development) }\end{array}$ \\
& distribution) & $\begin{array}{l}\text { Netflix (algorithm } \\
\text { development) }\end{array}$ \\
\hline
\end{tabular}


Table 2: Fit of community-based innovation at Phase I of the technology life cycle

\begin{tabular}{|c|c|c|c|}
\hline \multirow{2}{*}{$\begin{array}{l}\text { Characteristics } \\
\text { of innovation } \\
\text { at Phase I }\end{array}$} & \multicolumn{3}{|c|}{ Form of community-based innovation } \\
\hline & $\begin{array}{c}\text { Self-organized } \\
\text { community (SOC)* }\end{array}$ & $\begin{array}{l}\text { Firm-community } \\
\text { collaboration (FCC) }\end{array}$ & $\begin{array}{l}\text { Innovation contests \& } \\
\text { crowdsourcing (ICC) }\end{array}$ \\
\hline $\begin{array}{l}\text { Knowledge } \\
\text { distribution: } \\
\text { Ambiguous and } \\
\text { varied across } \\
\text { firms and } \\
\text { communities }\end{array}$ & $\begin{array}{c}\text { Higher fit } \\
\text { With higher decision- } \\
\text { rights, SOC members free } \\
\text { to explore varied } \\
\text { knowledge domains }\end{array}$ & $\begin{array}{c}\text { Lower fit } \\
\text { With shared decision } \\
\text { rights, FCC members and } \\
\text { firm members may not } \\
\text { explore broad knowledge } \\
\text { domain }\end{array}$ & $\begin{array}{l}\text { Lower fit } \\
\text { With lower decision rights, } \\
\text { ICC members may not be } \\
\text { free to explore broad } \\
\text { knowledge domains }\end{array}$ \\
\hline $\begin{array}{l}\text { Task } \\
\text { decomposition: } \\
\text { Very low with } \\
\text { integral tasks } \\
\text { common }\end{array}$ & $\begin{array}{c}\text { Higher fit } \\
\text { With higher interaction } \\
\text { between members, SOC } \\
\text { members can work on } \\
\text { integral tasks }\end{array}$ & $\begin{array}{l}\text { Lower fit } \\
\text { With possibly lower } \\
\text { interaction between } \\
\text { members, FCC members } \\
\text { may find it challenging to } \\
\text { work on integral tasks }\end{array}$ & $\begin{array}{c}\text { Lower fit } \\
\text { With typically lower levels } \\
\text { interaction between } \\
\text { members than SOC, ICC } \\
\text { members may find it } \\
\text { challenging to work on } \\
\text { integral tasks }\end{array}$ \\
\hline $\begin{array}{l}\text { Performance } \\
\text { trajectory: } \\
\text { Initially limited } \\
\text { advances with } \\
\text { later positive } \\
\text { returns }\end{array}$ & $\begin{array}{l}\text { Higher fit } \\
\text { With higher intrinsic } \\
\text { motivation, SOC members } \\
\text { can sustain efforts despite } \\
\text { initial limited advances }\end{array}$ & $\begin{array}{c}\text { Lower fit } \\
\text { With lower intrinsic } \\
\text { motivation, FCC members } \\
\text { may not sustain efforts } \\
\text { under limited advances }\end{array}$ & $\begin{array}{l}\text { Lower fit } \\
\text { With their higher focus on } \\
\text { extrinsic rewards, ICC } \\
\text { members may not sustain } \\
\text { efforts under limited } \\
\text { advances }\end{array}$ \\
\hline
\end{tabular}

Notes: * indicates expected dominant community based on best overall fit to characteristics of innovation 
Table 3: Examples of changes in dominant communities across first two phases of the technology life cycle

\begin{tabular}{lll}
\hline $\begin{array}{l}\text { Technological } \\
\text { setting }\end{array}$ & \multicolumn{1}{c}{$\begin{array}{c}\text { Dominant community in Phase I: } \\
\text { Pre-dominant design }\end{array}$} & \multicolumn{1}{c}{$\begin{array}{c}\text { Dominant community in Phase II: } \\
\text { Post-dominant design }\end{array}$} \\
\hline $\begin{array}{l}\text { Software } \\
\text { development }\end{array}$ & $\begin{array}{l}\text { Self-organized community (SOC): } \\
\text { Communities focused on open-source } \\
\text { software (OSS) challenged firms } \\
\text { embracing proprietary software, with } \\
\text { OSS for server software established as } \\
\text { dominant design. }\end{array}$ & $\begin{array}{l}\text { Firm-community collaboration (FCC): } \\
\text { Collaborations emerged such as in } \\
\text { software distribution (e.g. Red Hat) and } \\
\text { with firms embracing Linux (e.g. Google } \\
\text { Android) }\end{array}$ \\
$\begin{array}{l}\text { Consumer 3D } \\
\text { printing }\end{array}$ & $\begin{array}{l}\text { Self-organized community (SOC): } \\
\text { Communities such as RepRap emerged to } \\
\text { compete with firms, with Fused }\end{array}$ & $\begin{array}{l}\text { Firm-community collaboration (FCC): } \\
\text { Collaborations emerged such as in } \\
\text { MakerBot firm aligning with Thingiverse } \\
\text { composition Modeling (FDM) technique } \\
\text { established as dominant design }\end{array}$ \\
\hline
\end{tabular}


Table 4: Fit of community-based innovation at Phase II of the technology life cycle

\begin{tabular}{|c|c|c|c|}
\hline \multirow{2}{*}{$\begin{array}{l}\text { Characteristics } \\
\text { of innovation } \\
\text { at Phase II }\end{array}$} & \multicolumn{3}{|c|}{ Form of community-based innovation } \\
\hline & $\begin{array}{c}\text { Self-organized } \\
\text { community (SOC) }\end{array}$ & $\begin{array}{l}\text { Firm-community } \\
\text { collaboration (FCC)* }\end{array}$ & $\begin{array}{l}\text { Innovation contests \& } \\
\text { crowdsourcing (ICC) }\end{array}$ \\
\hline $\begin{array}{l}\text { Knowledge } \\
\text { distribution: } \\
\text { Consolidating } \\
\text { across firms } \\
\text { and } \\
\text { communities }\end{array}$ & $\begin{array}{c}\text { Lower fit } \\
\text { With higher decision- } \\
\text { rights, SOC members may } \\
\text { stay within knowledge } \\
\text { domain of less relevance } \\
\text { post dominant-design }\end{array}$ & $\begin{array}{l}\text { Higher fit } \\
\text { With shared decision } \\
\text { rights, FCC members and } \\
\text { firm members can } \\
\text { coordinate efforts around a } \\
\text { consolidating knowledge } \\
\text { domain }\end{array}$ & $\begin{array}{c}\text { Mixed fit } \\
\text { With lower decision rights, } \\
\text { ICC members rely on firm } \\
\text { to be directed with how to } \\
\text { contribute to new } \\
\text { knowledge domain }\end{array}$ \\
\hline $\begin{array}{l}\text { Task } \\
\text { decomposition: } \\
\text { Increasing } \\
\text { ability to } \\
\text { decompose } \\
\text { tasks }\end{array}$ & $\begin{array}{c}\text { Lower fit } \\
\text { With higher focus on } \\
\text { interaction between } \\
\text { members than with firms, } \\
\text { SOC members may be less } \\
\text { efficient in working on } \\
\text { mid-range decomposable } \\
\text { tasks }\end{array}$ & $\begin{array}{l}\text { Higher fit } \\
\text { With interaction between } \\
\text { members and between } \\
\text { members and firms, FCC } \\
\text { members can coordinate } \\
\text { efforts on mid-range } \\
\text { decomposable tasks }\end{array}$ & $\begin{array}{c}\text { Lower fit } \\
\text { With lower interaction } \\
\text { between members than } \\
\text { FCC, ICC members may } \\
\text { struggle to coordinate } \\
\text { efforts on mid-range } \\
\text { decomposable tasks }\end{array}$ \\
\hline $\begin{array}{l}\text { Performance } \\
\text { trajectory: } \\
\text { Steady } \\
\text { advances of } \\
\text { performance }\end{array}$ & $\begin{array}{c}\text { Lower fit } \\
\text { With higher intrinsic } \\
\text { motivation, SOC members } \\
\text { may not value performance } \\
\text { advances in comparison } \\
\text { with other community } \\
\text { members }\end{array}$ & $\begin{array}{c}\text { Mixed fit } \\
\text { With a mix of intrinsic and } \\
\text { extrinsic rewards, FCC } \\
\text { members motivated to } \\
\text { sustain efforts under } \\
\text { performance advances }\end{array}$ & $\begin{array}{c}\text { Higher fit } \\
\text { With higher focus on } \\
\text { extrinsic rewards, ICC } \\
\text { members motivated to } \\
\text { sustain efforts as } \\
\text { performance advances }\end{array}$ \\
\hline
\end{tabular}

Notes: * indicates expected dominant community based on best overall fit to characteristics of innovation 
Table 5: Fit of community-based innovation at Phase III of the technology life cycle

\begin{tabular}{|c|c|c|c|}
\hline \multirow{2}{*}{$\begin{array}{l}\text { Characteristics } \\
\text { of innovation } \\
\text { at Phase III }\end{array}$} & \multicolumn{3}{|c|}{ Form of community-based innovation } \\
\hline & $\begin{array}{c}\text { Self-organized } \\
\text { community (SOC) }\end{array}$ & $\begin{array}{l}\text { Firm-community } \\
\text { collaboration (FCC) }\end{array}$ & $\begin{array}{l}\text { Innovation contests } \& \\
\text { crowdsourcing (ICC)* }\end{array}$ \\
\hline $\begin{array}{l}\text { Knowledge } \\
\text { distribution: } \\
\text { Perceived } \\
\text { redundant with } \\
\text { need for } \\
\text { exploration }\end{array}$ & $\begin{array}{c}\text { Lower fit } \\
\text { With higher decision- } \\
\text { rights, SOC members may } \\
\text { find it challenging to } \\
\text { explore areas outside of } \\
\text { their established knowledge } \\
\text { domain }\end{array}$ & $\begin{array}{l}\text { Lower fit } \\
\text { With shared decision } \\
\text { rights, FCC members and } \\
\text { firm members may have } \\
\text { developed overlapping } \\
\text { knowledge domains }\end{array}$ & $\begin{array}{l}\text { Higher fit } \\
\text { Using firm-based decision } \\
\text { rights to connect with } \\
\text { diverse communities, firms } \\
\text { can explore new knowledge } \\
\text { domains }\end{array}$ \\
\hline $\begin{array}{l}\text { Task } \\
\text { decomposition: } \\
\text { High within } \\
\text { mature } \\
\text { technologies }\end{array}$ & $\begin{array}{l}\text { Lower fit } \\
\text { With higher focus on } \\
\text { interaction between } \\
\text { members than with firms, } \\
\text { SOC members may be less } \\
\text { efficient in working on }\end{array}$ & $\begin{array}{c}\text { Mixed fit } \\
\text { Interaction between } \\
\text { members in FCC } \\
\text { communities may not be } \\
\text { valued for highly } \\
\text { decomposable tasks }\end{array}$ & $\begin{array}{l}\text { Higher fit } \\
\text { With highly decomposable } \\
\text { tasks, ICC members can be } \\
\text { given very specific tasks to } \\
\text { solve that do not rely on } \\
\text { communication between } \\
\text { members }\end{array}$ \\
\hline $\begin{array}{l}\text { Performance } \\
\text { trajectory: } \\
\text { Diminishing } \\
\text { returns }\end{array}$ & $\begin{array}{c}\text { Higher fit } \\
\text { With higher intrinsic } \\
\text { motivation, SOC members } \\
\text { may be able to sustain } \\
\text { effort under diminishing } \\
\text { returns }\end{array}$ & $\begin{array}{l}\text { Lower fit } \\
\text { With a mix of intrinsic and } \\
\text { extrinsic rewards, FCC } \\
\text { members may struggle to } \\
\text { sustain efforts under } \\
\text { diminishing returns }\end{array}$ & $\begin{array}{c}\text { Higher fit } \\
\text { With higher focus on } \\
\text { extrinsic rewards, firms can } \\
\text { set rewards for ICC } \\
\text { members that reward } \\
\text { exploration }\end{array}$ \\
\hline
\end{tabular}

Notes: * indicates expected dominant community based on best overall fit to characteristics of innovation 